\title{
Associations of High Density Lipoprotein Cholesterol and Framingham Cardiovascular Risk with Diabetic Retinopathy in African Type 2 Diabetics
} \author{
Stephen Cook ${ }^{5}$, Emmanuel Mve Mengome ${ }^{6}$ \\ ${ }^{1}$ Faculty of Health Sciences, Walter Sisulu University, Mthatha, South Africa \\ ${ }^{2}$ Department of Ophthalmology, University of Kinshasa, Kinshasa, Congo \\ ${ }^{3}$ Emergency Service, University Hospital Centre, Brazzaville, Congo \\ ${ }^{4}$ School of International Studies, Wenzhou Medical College, Wenzhou, China \\ ${ }^{5}$ The Eye Centre, East London, South Africa \\ ${ }^{6}$ Faculty of Medicine, University of Health Sciences, Libreville, Gabon \\ Email: longombenza@gmail.com
}

Benjamin Longo-Mbenza ${ }^{1 *}$, Moise Mvitu Muaka², Thierry Gombet ${ }^{3}$, Igor Longo Phemba ${ }^{4}$,

Received 7 March 2014; revised 9 April 2014; accepted 17 April 2014

Copyright (C) 2014 by authors and Scientific Research Publishing Inc.

This work is licensed under the Creative Commons Attribution International License (CC BY).

http://creativecommons.org/licenses/by/4.0/

(c) (i) Open Access

\section{Abstract}

Objectives: To assess the associations of high density lipoprotein cholesterol (HDL-C) and Framingham cardiovascular (CVD) with diabetic retinopathy (DR). Methods: A cross-sectional study of random sample of 200 T2DM Central Africans. Sociobiographical, laboratory and eye examination main outcome measures were investigated using Tertiles of HDL-C (stratification = lowest < $40 \mathrm{mg} / \mathrm{dL}$, normal or interdemiate $=40-74.9 \mathrm{mg} / \mathrm{dL}$, highest $\geq 75 \mathrm{mg} / \mathrm{dL}$ ) and Framingham risk stratification $(<10 \%$ and $\geq 10 \%)$ by logistic regression models. Results: Out of 200 T2DM patients, $120(35.5 \%)$ had DR and out of DR patients, $116(\mathrm{n}=96.7 \%)$ had VD. There was a significant Ushaped relationship between DR rates and HDL-C stratification. In the normal HDL-C group, elevated 8-hydroxydeoxyguanosine and 10-year Framingham risk $>10 \%$ were the significant independent determinants for DR. In the highest HDL-C group, smoking status and 10-year Framingham risk $\geq 10 \%$ were the significantly independent determinants for DR. In 10-year Framingham risk $\geq 10 \%$ group, smoking status, insulin resistance and increasing levels of HDL-C were the significantly independent determinants for DR. Conclusion: DR and VD remain a public health problem in T2DM Central Africans. Some Central Africans with DR and VD appear to have higher HDL-C than T2DM Central Africans without DR and VD. HDL-C in T2DM patients with DR, may be tightly

\footnotetext{
${ }^{*}$ Corresponding author.
}

How to cite this paper: Longo-Mbenza, B., et al. (2014) Associations of High Density Lipoprotein Cholesterol and Framingham Cardiovascular Risk with Diabetic Retinopathy in African Type 2 Diabetics. World Journal of Cardiovascular Diseases, 4, 179-188. http://dx.doi.org/10.4236/wjcd.2014.44026 
controlled by genetic factors (black Bantu ethnicity) than the other lipoproteins as reported among Indians, African-Americans, and Japanese individuals. The most preventable environmental risk factors for DR were smoking status, global cardiovascular disease risk, insulin resistance and oxidative stress.

\title{
Keywords
}

\author{
Diabetic Retinopathy, Visual Disability, Higher High Density Lipoprotein, Smoking, Insulin \\ Resistance, Oxidative Stress, Africans
}

\section{Introduction}

Noncommunicable diseases including cardiovascular disease (CVD) and type 2 diabetes mellitus (T2DM) are a major cause of morbidity and premature mortality throughout the world. The global threat from CVD and T2DM is well established [1]-[9]. Furthermore, an overlap of risk factors between CVD and diabetic retinopathy (DR) is increasingly reported [1]-[11]. DR is the most frequent cause of visual disability (VD) worldwide.

The Framingham cardiovascular risk score (Total CVD) is often defined as the probability of an individual's experience with a CVD event over 10 years [9]-[12]. Among different tools, high density lipoprotein (HDL-C) hypocholesterolemia predicts the absolute risk of CVD [9]-[12], T2DM [9], and metabolic syndrome [13].

However, higher levels of HDL-C have been reported atherogenic (macrovascular lesions) in black Central Africans [14]-[16], and associated with any DR in India people with 10-year Framingham Risk Score > 10\% [10].

The lack of data of this paradoxical association with microvascular complications and VD in Central Africans, justified the initiation of this research.

The objectives of this study were to assess the associations of high density lipoprotein cholesterol (HDL-C) and Framingham cardiovascular (CVD) with diabetic retinopathy (DR) and/or visual disability.

\section{Materials and Methods}

This was a community-based, cross-sectional study comprising 200 black T2DM patients, 20 years of age and older, and undertaken in Kinshasa Region, DRC, from October to December, 2010.

All eligible T2DM patients completed the structured and standardized interview and examination at Saint Joseph Hospital, Division of Ophthalmology, Kinshasa, DRC.

All study procedures adhered to the principles of the Declaration of Helsinki for research involving human participants. We obtained written proper consent from all study participants before data collection and approval from the Lomo Medical Center Institutional Review Board, Kinshasa, DRC.

The participants were selected by multistage system random sampling, based on the districts level of urbanization, which made the sample a true representation of Kinshasa Region.

\subsection{Clinical Procedures}

Participants underwent interviews, brief physical examination, laboratory measurements, and comprehensive ophthalmic examination. Detailed history included sociobiographical factors such as age, gender, residence, cigarette smoking, diets, absence of CVD, ethnicity, insulin therapy, education level, alcohol intake, and socioeconomic status (SES).

Standards were used to measure weight, height, waist-circumference, systolic blood pressure (SBP), and diastolic blood pressure (DBP).

A specialist on retina laser performed a detailed ocular history and a comprehensive eye examination, including stereo fundus photographs. All participants were selected without previous interventions for DR, corneal opacity or lenticular opacities, type 1 diabetes, neither pregnancy for women.

Laboratory evaluation consisted of measuring fasting plasma glucose (FPG), serum HDL-C, triglycerides, total cholesterol, apolipoprotein B (ApoB), low density lipoprotein (LDL)-C, insulin, vitamin C, vitamin D, vitamin E, albumin, plasma 8-hydrpxydeoxyguanosine (8-OHdG), 8-Isoprostane, superoxide dismutase (SOD), thi- 
obarbuturic acid reacting substances (TBARS), and glycosylated hemoglobin (HbA1c). All clinical procedures are described in detail elsewhere [17] [18].

The 10-year Framingham CVD risk was estimated using information from the Framingham Heart Study such as age, gender, smoking status, SBP, serum total cholesterol and HDL-C [18]-[21].

\subsection{Definitions}

T2DM was defined according to the Expert Committee on the Diagnosis and Classification of Diabetes Mellitus (DM) [22].

The total CVD score was classified as 10-year Framingham high risk ( $\geq 10 \%)$, and 10-year Framingham low $(<10 \%)[18]$.

Overweight/overall obesity was defined by body mass index (Weight in $\mathrm{kg} /(\text { height in } \mathrm{m})^{2}$ ) $\geq 25 \mathrm{~kg} / \mathrm{m}^{2}$. Using International Diabetes Federation criteria (IDF Europe), metabolic syndrome (MS) was diagnosed in participants who had abdominal obesity (Waist $\geq 94 \mathrm{~cm}$ in men and $\geq 80 \mathrm{~cm}$ in women) plus two or more of the following abnormalities: FPG $\geq 100 \mathrm{mg} / \mathrm{dL}$, triglycerides $\geq 150 \mathrm{mg} / \mathrm{dL}$, low HDL-C $<40 \mathrm{mg} / \mathrm{dL}$ in men and $<50 \mathrm{mg} / \mathrm{dL}$ in women, $\mathrm{SBP} \geq 130 \mathrm{mmHg}$ or $\mathrm{DBP} \geq 85 \mathrm{mmHg}$ [23].

Stratification of HDL-C was defined in 3 groups: low with HDL-C $<40 \mathrm{mg} / \mathrm{dL}$, normal with HDL-C = 40 $74.9 \mathrm{mg} / \mathrm{dL}$, and high HDL-C $\geq 75 \mathrm{mg} / \mathrm{dL}$ according to criteria of MS modified and validated for Africans [14]-[16].

The relative homeostasis model-based insulin resistance (HOMA-IR) was calculated using the formula of Mathews: HOMA-IR $=$ (fasting insulin $\times$ fasting plasma glucose)/405 [24]. HOMA-IR $\geq 2.5$ is the optimal cutoff point (Sensitivity $=93.3 \%$ and Specificity $=100 \%$ ) to define insulin resistance in Central Africans [25] .

Lack of clinical management of T2DM included no glycemic control by FPG $\geq 126 \mathrm{mg} / \mathrm{dL}$ and no HbA1c control with $\mathrm{HbA} 1 \mathrm{c} \geq 7 \%$.

DR was defined based on the modified Klein classification of the Early Treatment Diabetic Retinopathy Study Scale with severe non-proliferative DR, proliferative DR (PDR) and clinically significant macular edema (DME), grading done by two independent investigators in a masked fashion [26] with excellent grading agreement (kappa $=0.864)$.

Severe non proliferative diabetic retinopathy (NPDR), proliferative diabetic retinopathy (PDR) and/or DME using the classification are modified by the Early Treatment Diabetic Retinopathy Study [27]. Visual disability (VD) was defined as blindness and visual impairment (low vision) using the World Health Organization and explained in our previous studies [17] [18].

\subsection{Statistical Analysis}

Data were presented as proportions (\%) for categorical variables and mean \pm standard deviation for continuous variables.

The univariate association between variables and DR was assessed by comparing percentages using the Chisquare test, comparing means using the Student t-test, and Odds ratio (OR) and 95\% confidence interval (95\% CI) using contingency tables.

The multivariate analysis such as logistic regression models (Stepwise, Forward Wald) was used to assess the independent association between DR and putative determinants in avoiding collinearity and adjusting for confounding factors in all participants, among all, low HDL-C group, normal HDL-C group, high HDL-C group, and 10-year Framingham risk $\geq 10 \%$ group.

All statistical analyses were two-sided and a P-value $<0.05$ was considered statistically significant. Data analysis was carried out using the Statistical Package for social Sciences (SPSS) for Windows version 19 (SPSS Inc, Chicago, IL, USA).

\section{Results}

\subsection{Prevalence of DR}

Out of 200 T2DM patients, 120 (35.5\%) had DR and out of DR patients, $116(\mathrm{n}=96.7 \%)$ had VD. There was a significant $(\mathrm{P}<0.0001)$ U-shaped relationship between DR rates and HDL-C stratification: the highest $(57.8 \% \mathrm{n}$ $=9 / 20)$, the intermediate $(45 \% n=25 / 116)$, and the lowest $(21.6 \% n=25 / 116)$ rates of DR being concurrent with highest HDL-C group, lowest. 


\subsection{Univariate Association of Risk Indicators}

Univariate association of DR with sociobiographical and lifestyle factors is presented in Table 1. Gender, abdominal obesity, larger PP, alcohol intake, migration, age of T2DM onset, and overweight/obesity did not have a statistically significant association with DR. However, higher rates of history of smoking status, MS, insulin therapy, low intake of Fumbwa leaves, low education level, no glycemic control, low intake of beans, no HbA1c control, and low SES were significantly associated with DR (Table 1).

The association of cardiometabolic and oxidative stress factors with presence of DR by univariate analysis is presented in Table 2. For cardiometabolic effect, there was a significant univariate association between insulin resistance, elevated ApoB, high 10-year Framingham risk including low HDL-C, and DR presence. However, low HDL-C was not significantly associated with DR. Except paradoxical association between elevated SOD and DR presence, the rest of markers of imbalance of oxidant/antioxidant (deficiency of serum vitamins D, C and $\mathrm{E}$ and albumin, but elevated levels of 8-OHdG, 8-Isoprostane and TBARS) were significantly associated with DR presence.

\subsection{Independent Determinants of DR}

No independent variables were included in the first model of logistic regression performed to explain (predict) DR in T2DM patients with low HDL-C.

After adjusting for smoking status, insulin therapy, education level, insulin resistance, HbA1c control, serum albumin, and MS, Table 3 presents the results of the second stepwise logistic regression analysis in T2DM patients with normal HDL-C. The presence of DR was independently associated with elevated 8-OHdG (marker of oxidative stress) and high 10-year Framingham risk.

Table 4 shows the findings of the third stepwise logistic regression analysis in T2DM patients with high HDL-C. After adjusting for education level, insulin resistance, HbA1c control, MS, serum albumin and 8-OHdG, only smoking status and high 10-year Framingham risk were independently associated with DR prevalence among participants with high HDL-C.

In considering continuous levels of HDL-C, three factors were significantly associated with DR in T2DM patients with 10-year Framingham risk $\geq 10 \%$ (Table 5). Indeed, in the fourth model of the stepwise logistic regression after adjusting for insulin therapy, education level, HbA1c control, serum albumin, vitamin C, and 8OHdG, the multivariate risk (Odds) of DR in group with high Framingham CVD risk, was multiplied by 5 times, 10 times and 3.4\% excess by smoking status, insulin resistance, and increase in $1 \mathrm{mg}$ of HDL-C, respectively.

\section{Discussion}

This study was conducted to estimate the prevalence of VD, DR and its sight-threatening end points (PDR and DME) as well as the relationship between independent determinants and DR.

\subsection{Prevalence}

These findings were related to a representative estimates on the prevalence for VD, DR and VTDR among T2DM Central Africans. Prevalences of 35\% for DR and 13\% for VTDR were valid using photography and similar to global estimates of any DR of $34.6 \%$ and $14 \%$ of VTDR [28]. DR prevalences vary considerably worldwide because ethnic groups, races, periods, SES, methodologies, environment, and sample size [28]-[30].

Various criteria used in ascertaining Diabetes mellitus status and types may also explain the disparities of DR prevalences estimated worldwide [28]-[33].

The present study showed unexpected high estimates for VD prevalence which was $31 \%$. Furthermore, VD, DR and sight threatening complication of T2DM disproportionately and specifically affect black Central Africans as reported from racial and ethnic populations from other continents [34] [35].

\subsection{Univariate Risk Indicators for DR}

\subsubsection{U-Shaped Relationship between DR, VD, and HDL-C Stratification}

Reverse epidemiology was suggested by U-shaped relationship between rates of DR, VD, and HDL-C stratification among these T2DM Central Africans. Type 2 diabetic Central Africans exhibit very high rates of uncontrolled diabetes, atherosclerotic complications, insulin resistance, and metabolic syndrome at both low and very 
Table 1. Association between sociobiographical and lifestyle factors and DR.

\begin{tabular}{|c|c|c|c|}
\hline Variables of interest & $\begin{array}{c}\text { Presence of DR } \\
\mathbf{n}=71 \\
\mathbf{n}(\%)\end{array}$ & $\begin{array}{c}\text { Absence of DR } \\
n=128 \\
n(\%)\end{array}$ & P-value \\
\hline Gender & & & 0.562 \\
\hline Men & 30 (42.3) & $60(46.5)$ & \\
\hline Women & $41(57.7)$ & 69 (53.3) & \\
\hline Abdominal obesity & $36(50.7)$ & $56(43.4)$ & 0.322 \\
\hline Smoking & $26(36.6)$ & $10(7.8)$ & $<0.0001$ \\
\hline Alcohol intake & $15(21.1)$ & $33(25.6)$ & 0.480 \\
\hline Metabolic Syndrome & $51(71.8)$ & 67 (51.9) & 0.006 \\
\hline Pulse pressure $\geq 60 \mathrm{mmHg}$ & $11(15.5)$ & $22(17.2)$ & 0.758 \\
\hline Migration & $29(40.8)$ & 38 (29.5) & 0.071 \\
\hline Insulin treatment & 39 (54.9) & $49(38)$ & 0.021 \\
\hline Late onset of T2DM & $28(39.4)$ & $48(37.2)$ & 0.756 \\
\hline Low intake of Fumbwa & $22(31.0)$ & $23(17.8)$ & 0.033 \\
\hline Low intake of beans & $29(40.8)$ & $36(27.9)$ & 0.044 \\
\hline Low education level & $55(77.5)$ & $73(56.6)$ & 0.003 \\
\hline Low SES & $51(71.8)$ & $74(57.4)$ & 0.043 \\
\hline Overweight/obesity & $43(60.6)$ & $84(65.1)$ & 0.522 \\
\hline DM duration $\geq 7$ years & $29(38.2)$ & 47 (61.8) & 0.539 \\
\hline $\mathrm{HbA} 1 \mathrm{c} \geq 7 \%$ (no control) & $47(66.2)$ & $54(41.9)$ & $<0.001$ \\
\hline FPG $\geq 126$ mg/dL (no control) & $53(74.6)$ & $72(55.8)$ & 0.008 \\
\hline
\end{tabular}

Table 2. Association of oxidant/antioxidant status and cardiometabolic factors with DR.

\begin{tabular}{cccc}
\hline Variables of interest & $\begin{array}{c}\text { Presence of DR } \\
\mathbf{n = 7 1} \\
\mathbf{n}(\mathbf{\%})\end{array}$ & $\begin{array}{c}\text { Absence of DR } \\
\mathbf{n = 1 2 8} \\
\mathbf{n}(\mathbf{\%})\end{array}$ & P-value \\
\hline Vitamin D deficiency & $65(91.5)$ & $88(68.2)$ & $<0.0001$ \\
Vitamin E deficiency & $70(98.6)$ & $91(70.5)$ & $<0.0001$ \\
Vitamin C deficiency & $62(87.3)$ & $76(58.9)$ & $<0.0001$ \\
Elevated SOD & $46(64.8)$ & $39(30.2)$ & $<0.0001$ \\
Elevated 8-OHdG & $62(87.3)$ & $60(46.5)$ & $<0.0001$ \\
Elevated 8-Isoprostane & $62(87.3)$ & $52(42.6)$ & 0.0001 \\
Insulin resistance (IR) & $49(69)$ & $35(27.1)$ & $<0.0001$ \\
Elevated ApoB & $52(73.2)$ & $64(49.6)$ & $<0.001$ \\
HDL-C (low) & $31(43.7)$ & $64(49.6)$ & 0.420 \\
Albumin (low level) & $48(67.6)$ & $71(51)$ & 0.056 \\
Elevated TBARS & $65(91.5)$ & $79(61.2)$ & $<0.0001$ \\
10-year Framingham risk & & & $<0.0001$ \\
$\geq 10 \%$ & $53(74.6)$ & $25(19.4)$ & \\
<10\% & $18(25.4)$ & $25(80.6)$ & \\
\hline
\end{tabular}

Table 3. Independent determinants of DR prevalence among type 2 diabetics with normal HDL-C.

\begin{tabular}{cccccc}
\hline & B Coefficient & Standard error & Wald Chi-square & OR (95\% CI) & P-value \\
\hline $\begin{array}{c}\text { Independent variables } \\
\text { 8-OHdG }\end{array}$ & 1.658 & 0.562 & 8.717 & $5.3(1.8-15.8)$ & 0.003 \\
$\begin{array}{c}\text { Elevated vs. normal } \\
\begin{array}{c}10-\text {-year Framingham risk } \\
\geq 10 \% \text { vs. }<10 \%\end{array}\end{array}$ & 1.543 & 0.547 & 7.950 & $4.7(1.6-13.7)$ & 0.005 \\
$\quad$ Constant & -2.703 & 0.503 & 28.896 & & $<0.0001$ \\
\hline
\end{tabular}


Table 4. Independent determinants for DR among type 2 diabetics with high HDL-C.

\begin{tabular}{cccccc}
\hline & B Coefficient & Standard error & Wald Chi-square & OR (95\% CI) & P-value \\
\hline $\begin{array}{c}\text { Independent variables } \\
\text { Smoking Yes vs. No }\end{array}$ & 1.833 & 0.747 & 6.021 & $6.3(1.5-27)$ & 0.014 \\
$\begin{array}{c}10 \text {-year Framingham risk } \\
\quad \begin{array}{l}\text { 10\% vs. }<10 \% \\
\text { Constant }\end{array}\end{array}$ & 2.236 & 0.752 & 8.830 & $9.4(2.1-40.9)$ & 0.003 \\
\hline
\end{tabular}

Adjusted for education level, insulin resistance, HbA1c, serum albumin, MS, and 8-OHdG.

Table 5. Independent association between smoking, IR, increase in unit of HDL-C and prevalent DR among type 2 diabetics with 10 -year Framingham risk $\geq 10 \%$.

\begin{tabular}{cccccc}
\hline & B Coefficient & Standard error & Wald Chi-square & OR (95\% CI) & P-value \\
\hline Independent variables & & & & & \\
Smoking Yes vs. No & 1.611 & 0.653 & 6.091 & $5(1.4-18)$ & 0.014 \\
IR Yes vs. No & 2.296 & 0.830 & 7.499 & $9.9(1.9-51.4)$ & 0.006 \\
HDL-C & 0.033 & 0.018 & 3.419 & $1.034(1.001-1.1)$ & 0.049 \\
\hline
\end{tabular}

high HDL-C levels [36] [37].

According to the paper from Isezuo on native Africans with T2DM [38], our findings demonstrate that classical dichotomization of HDL-C (low/bad vs. high/good HDL-C) is controversial and not useful in the management of the cardiometabolic risk, VD, and DR.

Indeed, compared with high/good HDL-C level, low HDL-C level had similar neutral effect on DR prevalence in this study.

In not stratifying HDL-C and confirmed by other authors [1]-[11] [31]-[41], traditional cardiovascular disease (CVD) risk factors such as smoking status, MS, high 10-year Framingham risk, insulin therapy, low intake of vegetables (Fumbwa leaves, beans), low education, low SES, elevated ApoB, HbA1c no control, and FPG no control were individually and significantly associated with DR in all T2DM patients.

In considering new CVD risk factors such as biomarkers, tools for diagnosis, treatment and prevention in personalized medicine, the present univariate analysis reported an increased oxidative stress and impaired antioxidant defense significantly associated with DR in these T2DM Central Africans.

The oxidant/antioxidant imbalance was characterized by elevated serum levels of 8-OHdG, TBARS and 8Isoprostane, but deficiencies of serum levels of vitamin D, albumin, vitamin C, and vitamin E. Experimental and clinical studies suggest that the retinas display oxidant/antioxidant imbalance and more extensive membrane lipid peroxidation (TBARS, 8-Isoprostant) and oxidative DNA damage (8-OHdG) which are the consequences of reactive oxygen species-induced injury [42]-[45]. We were cautious to explain positive association between DR and SOD in this study. Potential adaptative mechanisms are suggested to encounter DR by increase in SOD.

\subsubsection{Independent Determinants of DR by Stratifying HDL-C Levels}

The paradox between HDL-C dichotomization and DR or VD urged us to stratify HDL-C in three groups among these black T2DM patients.

In low HDL-C group, variables were all independently associated with DR presence in this study. However, in T2DM patients with higher 10-year Framingham risk including low HDL-C concentrations, smoking status, insulin resistance, and increase in each unit of HDL-C levels were independently associated with prevalent DR.

In normal HDL-C group, only smoking status and high 10-year Framingham risk were independently associated with DR prevalence. And in higher HDL-C group, both smoking status and high 10-year Framingham risk were independently associated with DR prevalence.

These paradoxical associations of a quantitative HDL-C trait could be dependent on genetic, ethnic, minority, and environmental (lifestyle changes: migration, urbanization, westernization, inappropriate diet, smoking, exaggerated physical activity, excessive alcohol intake) factors [41]-[52]. There are positive association between total cholesterol, the deficiency in cholesterol ester transfer protein (CETP), DR, poor control of HbA1c, insulin 
therapy, and increasing HDL-C levels in diabetic Africans [38] [46]-[48] people from developed countries [49]-[52] and Asians [8]. DNA mutation due to elevated 8-OHdG may also impact on HDL levels in these Central Africans.

\subsection{Clinical Implications}

Our findings will impact on modifiable factors associated with DR by integrating ophthalmic practice into Primary Health care systems, and the WHO "Vision 2020 initiative" in central Africa.

The most important modifiable risk factors for DR are smoking status [53], systolic blood pressure, total cholesterol, education, oxidative stress, control of T2DM, and diet.

Further studies on the effects of T2DM duration, genetics, aging, and HDL-C on DR are recommended in Africa. For Central Africans, we need urgent understanding of HDL particles which are heterogeneous and classified as a larger, less dense HDL2 or a smaller, denser HDL3 [54]. African-Americans present a different cardiovascular risk profile when compared with Caucasians: lower TG and higher HDL-C [55] [56]. Paraoxonase (PON1) enzyme activity 1 related to HDL dysfunctionality and responsible for the antioxidant and anti-inflammatory properties of HDL [57] [58], could be also investigated in Central Africans.

\subsection{Study Limitations}

The present study may be limited to some degree because of its cross-sectional design which is not able to show a causal association between the identified independent determinants and DR.

\section{Conclusion}

Patients of Central African ethnicity had a significant higher prevalence of DR, VD, and VTDR which constitute health public issues with peculiar risk indicators. Smoking status, metabolic syndrome, insulin therapy, low intake of Fumbwa leaves and beans, dyslipidemia, oxidant/antioxidant imbalance, low education level, low socioeconomic status, no HbA1c control and no glycemic control are the univariate risk indicators for DR. Ushaped relationship among DR, VD and HDL-C stratification and the independent association among elevated 8-OHdG, DNA mutation, high 10-year Framingham risk, smoking status, insulin resistance, and DR by HDL-C or Framingham risk stratification need further genetic studies among Central African T2DM patients.

\section{References}

[1] Haffner, S.M., Hazuda, H.P., Stern, M.P., Patterson, J.K., Van Heuven, W.A.J. and Fong, D. (1989) Effect of Socioeconomic Status on Hyperglycemia and Retinopathy Levels in Mexican Americans with NIDDM. Diabetes Care, 12, 128-134. http://dx.doi.org/10.2337/diacare.12.2.128

[2] Blaum, C.S., Velez, L., Hiss, R.G. and Halter, J.B. (1997) Characteristics Related to Poor Glycemic Control in NIDDM Patients in Community Practice. Diabetes Care, 20, 7-11. http://dx.doi.org/10.2337/diacare.20.1.7

[3] Harris, M.I., Eastman, R.C., Cowie, C.C., Flegal, K.M. and Eberhardt, M.S. (1999) Racial and Ethnic Differences in Glycemic Control of Adults with Type 2 Diabetes. Diabetes Care, 22, 403-408. http://dx.doi.org/10.2337/diacare.22.3.403

[4] The Expert Committee on the Diagnosis and Classification of Diabetes Mellitus (1977) Report of the Expert Committee on the Diagnosis and Classification of Diabetes Mellitus. Diabetes Care, 20, 1183-1197.

[5] Knuiman, M.W., Welborn, T.A., McCann, V.J., Stanton, K.G. and Constable, I.J. (1986) Prevalence of Diabetic Complications in Relation to Risk Factors. Diabetes, 35, 1332-1339. http://dx.doi.org/10.2337/diab.35.12.1332

[6] Kuusisto, J., Mykkanen, L., Pyorala, K. and Laakso, M. (1994) NIDDM and Its Metabolic Control Predict Coronary Heart Disease in Elderly Subjects. Diabetes, 43, 960-967. http://dx.doi.org/10.2337/diab.43.8.960

[7] Gilmer, T.P., O’Connor, P.J., Manning, W.G. and Rush, W.A. (1997) The Cost to Health Plans of Poor Glycemic Control. Diabetes Care, 20, 1847-1853. http://dx.doi.org/10.2337/diacare.20.12.1847

[8] Sasongko, M.B., Wong, T.Y., Nguyen, T.T., Kawasaki, R., Jenkins, A., Shaw, J. and Wang, J.J. (2011) Serum Apolipoprotein AI and B Are Stronger Biomarkers of Diabetic Retinopathy than Traditional Lipids. Diabetes Care, 34, 474-479. http://dx.doi.org/10.2337/dc10-0793

[9] Peter, R., Okoseime, O.E., Rees, A. and Owens, D.R. (2009) Postprandial Glucose-A Potential Therapeutic Target to Reduce Cardiovascular Mortality. Current Vascular Pharmacology, 7, 68-74. 
http://dx.doi.org/10.2174/157016109787354169

[10] Sivaprasad, S., Gupta, B., Crosby-Nwaobi, R. and Evans, J. (2012) Prevalence of Diabetic Retinopathy in Various Ethnic Groups: A Worldwide Perspective. Survey of Ophthalmology, 57, 347-370. http://dx.doi.org/10.1016/j.survophthal.2012.01.004

[11] Harris, M.I. (1995) Health Insurance and Diabetes. In: Harris, M.I., Cowie, C.C., Reiber, G., Boyko, E., Stem, M. and Bennett, P., Eds., Diabetes in America, 2nd Edition, Government Printing Office, Washington DC, 591-600.

[12] Damkondwar, D.R., Raman, R., Suganeswari, G., Kulothungan, V. and Sharma, T. (2012) Assessing Framingham Cardiovascular Risk Scores in Subjects with Diabetes and Their Correlation with Diabetic Retinopathy. Indian Journal of Ophthalmology, 60, 45-48. http://dx.doi.org/10.4103/0301-4738.91344

[13] Agirbasli, M., Agaoglu, N.B., Ergonul, O., Yagmur, I., Aydogar, H., Oneri, T. and Ozturk, O. (2011) Comparison of Anthropometric Indices in Predicting Metabolic Syndrome Components in Children. Metabolic Syndrome and Related Disorders, 9, 453-459. http://dx.doi.org/10.1089/met.2011.0018

[14] Gombet, T., Longo-Mbenza, B., Ellenga-Mbolla, B., Ikama, M.S., Mokondjimobe, E., Kimbally, K.G. and Nkoua, J.L. (2012) Aging, Female Sex, Migration, Elevated HDL-C, and Inflammation Are Associated with Prevalence of Metabolic Syndrome among African Bank Employees. International Journal of General Medicine, 5, 495-503.

[15] Kalk, W.J. and Joffe, B.I. (2008) The Metabolic Syndrome, Insulin Resistance, and Its Surrogates in African and White Subjects with Type 2 Diabetes in South Africa. Metabolic Syndrome and Related Disorders, 6, 247-255. http://dx.doi.org/10.1089/met.2008.0003

[16] Davie, S.J., Gould, B.J. and Yudkin, J.S. (1992) Effect of Vitamin C on Glycosylation of Proteins. Diabetes, 41, 167173. http://dx.doi.org/10.2337/diab.41.2.167

[17] Longo-Mbenza, B., Muaka, M.M., Yokobo, E.C., Phemba, I.L., Mokondjimobe, E., Gombet, T., Ndembe, D.K., Mona, D.T. and Masamba, S.W. (2012) Effects of Biomarkers of Oxidative Stress Damage on Prevalence and Severity of Visual Disability among Black Central Africans. Molecular Vision, 18, 1619-1628.

[18] Longo-Mbenza, B., Muaka, M.M., Mokondjimobe, E., Ndembe, D.K., Mona, D.T. and Buassa-bu-Tsumbu, B. (2012) Oxidative Stress Related-Elevated High Gamma Glutamyl Transferase Levels, and Aging, Intake of Tropical Food Plants, Migration and Visual Disability in Central Africans. International Journal of Ophthalmology, 5, 493-498.

[19] Villines, T.C. and Taylor, A.J. (2012) Multi-Ethnic Study of Atherosclerosis Arterial Age versus Framingham 10-Year or Lifetime Cardiovascular Risk. American Journal of Cardiology, 110, 1627-1630. http://dx.doi.org/10.1016/j.amjcard.2012.07.018

[20] Myerson, M., Coady, S., Taylor, H., Rosamond, W.D., Goff Jr., D.C. and ARIC Investigators (2009) Declining Severity of Myocardial Infarction from 1987 to 2002: The Atherosclerosis Risk in Communities (ARIC) Study. Circulation, 119, 503-514. http://dx.doi.org/10.1161/CIRCULATIONAHA.107.693879

[21] Chamnan, P., Simmons, R.K., Sharp, S.J., Griffin, S.J. and Wareham, N.J. (2009) Cardiovascular Risk Assessment Scores for People with Diabetes: A Systemic Review. Diabetologia, 52, 2001-2014. http://dx.doi.org/10.1007/s00125-009-1454-0

[22] Expert Committee on the Diagnosis and Classification of Diabetes Mellitus (2003) Report of the Expert Committee on the Diagnosis and Classification of Diabetes Mellitus. Diabetes Care, 26, S5-S20.

http://dx.doi.org/10.2337/diacare.26.2007.S5

[23] IDF (2006) A Consensus Statement from the International Diabetes Federation. Diabet Med, 23, 469-480.

[24] Friedwald, W.T., Levy, R.I. and Fredrickson, D.S. (1972) Estimation of the Concentration of Low-Density Lipoprotein Cholesterol in Plasma, without Use of the Preparative Ultracentrifuge. Clinical Chemistry, 18, 499-502.

[25] Longo-Mbenza, B., Nkongo Mvindu, H., Kasiam On’kin, J.B., Bikuku, N., Kianu Phanzu, B., Nge Okwe, A. and Kabangu, N. (2011) The Deleterious Effects of Physical Inactivity on Elements of Insulin Resistance and Metabolic Syndrome in Central Africans at High Cardiovascular Risk. Diabetes \& Metabolic Syndrome: Clinical Research Review, 5, 1-6.

[26] Agarwal, S., Raman, R., Paul, P.G., et al. (2005) Sankara Nethralaya_Diabetic Retinopathy Epidemiology and Molecular Genetic Study (SN_DREAMS 1): Study Design and Research Methodology. Ophthalmic Epidemiology, 12, 143-153. http://dx.doi.org/10.1080/09286580590932734

[27] Kawasaki, R., Cheung, N., Islam, F.M., Klein, R., Klein, B.E., Cotch, M.F., Sharrett, A.R., O’Leary, D. and Wong, T.Y. (2011) Is Diabetic Retinopathy Related to Subclinical Cardiovascular Disease? Ophthalmology, 118, 860-865. http://dx.doi.org/10.1016/j.ophtha.2010.08.040

[28] Yau, J.W., Rogers, S.L., Kawasaki, R., Lamoureux, E.L., Kowalski, J.W., Bek, T., Chen, S.J., Dekker, J.M., Fletcher, A., Grauslund, J., Haffner, S., Hamman, R.F., Ikram, M.K., Kayama, T., Klein, B.E., Klein, R., Krishnaiah, S., Mayurasakorn, K., O’Hare, J.P., Orchard, T.J., Porta, M., Rema, M., Roy, M.S., Sharma, T., Shaw, J., Taylor, H., Tielsch, J.M., Varma, R., Wang, J.J., Wang, N., West, S., Xu, L., Yasuda, M., Zhang, X., Mitchell, P., Wong, T.Y. and Meta- 
Analysis for Eye Disease (META-EYE) Study Group (2012) Global Prevalence and Major Risk Factors of Diabetic Retinopathy. Diabetes Care, 35, 556-564. http://dx.doi.org/10.2337/dc11-1909

[29] Liew, G., Klein, R. and Wong, T.Y. (2009) The Role of Genetics in Susceptibility to Diabetic Retinopathy. International Ophthalmology Clinics, 49, 35-52. http://dx.doi.org/10.1097/IIO.0b013e31819fd5d7

[30] Zhang, X., Saaddine, J.B., Chou, C.F., Cotch, M.F., Cheng, Y.J., Geiss, L.S., Gregg, E.W., Albright, A.L., Klein, B.E. and Klein, R. (2010) Prevalence of Diabetic Retinopathy in the United States, 2005-2008. JAMA, 304, 649-656. http://dx.doi.org/10.1001/jama.2010.1111

[31] Sivaprasad, S., Gupta, B., Crosby-Nwaobi, R. and Evans, J. (2010) Prevalence of Diabetic Retinopathy in Various Ethnic Groups: A Worldwide Perspective. Survey of Ophthalmology, 57, 347-370. http://dx.doi.org/10.1016/j.survophthal.2012.01.004

[32] Sivaprasad, S., Gupta, B., Gulliford, M.C., Dodhia, H., Mann, S., Nagi, D. and Evans, J. (2012) Ethnic Variation in the Prevalence of Visual Impairment in People Attending Diabetic Retinopathy Screening in the United Kingdom (DRIVE UK). PLoS ONE, 7, Article ID: e39608. http://dx.doi.org/10.1371/journal.pone.0039608

[33] Nsiah-Kumi, P., Ortmeier, S.R. and Brown, A.E. (2009) Disparities in Diabetic Retinopathy Screening and Disease for Racial and Ethnic Minority Populations: A Literature Review. Journal of the National Medical Association, 101, 430437.

[34] Muaka, M.M., Longo-Mbenza, B. and Kaimbo wa Kaimbo, D. (2009) Frequency and the Causes of Blindness and Visual Impairment among Patients with Diabetes Mellitus from DR Congo. Le Mali Médical, 24, 22-26.

[35] Moukouri, E.D.N., Moli, T. and Nouedoui, C. (1992) Les aspects épidémiologiques de la rétinopathie diabétique à Yaoundé. Médecine d'Afrique Noire, 39, 327-334.

[36] Longo-Mbenza, B., Muaka, M.M., Mbenza, G., Mbungu-Fuele, S., Mabwa-Mbalanda, L., Nzuzi Babeki, V. and Mbadi-A-Sungu, J. (2008) Risk Factors of Poor Control of HBA1c and Diabetic Retinopathy: Paradox with Insulin Therapy and High Values of HDL in African Diabetic Patients. International Journal of Diabetes and Metabolism, 16, 69-78.

[37] Longo-Mbenza, B., Kasiam Lasi On’kin, J.B., Nge Okwe, A. and Kangola Kabangu, N. (2011) The Metabolic Syndrome in a Congolese Population and Its Implications for Metabolic Syndrome Definitions. Diabetes \& Metabolic Syndrome: Clinical Research \& Reviews, 5, 17-24. http://dx.doi.org/10.1016/j.dsx.2010.05.009.

[38] Isezuo, S.A. (2005) Is High Density Lipoprotein Cholesterol Useful in Diagnosis of Metabolic Syndrome in Native Africans with Type 2 Diabetes? Ethnicity \& Disease, 15, 6-10.

[39] Omolase, C.O., Adekanle, O., Owoeye, J.F.A. and Omolase, B.O. (2010) Diabetic Retinopathy in a Nigerian Community. Singapore Medical Journal, 51, 56-59.

[40] Longo-Mbenza, B., Nkondi Nsenga, J. and Vangu Ngoma, D. (2007) Prevention of the Metabolic Syndrome Insulin Resistance and the Atherosclerotic Diseases in Africans Infected by Helicobacter pylori Infection and Treated by Antibiotics. International Journal of Cardiology, 121, 229-238. http://dx.doi.org/10.1016/j.ijcard.2006.12.003

[41] Damkondwar, D.R., Raman, R., Suganeswari, G., Kulothungan, V. and Sharma, T. (2012) Assessing Framingham Cardiovascular Risk Scores in Subjects with Diabetes and Their Correlation with Diabetic Retinopathy. Indian Journal of Ophthalmology, 60, 45-48. http://dx.doi.org/10.4103/0301-4738.91344

[42] Hartnett, M.E., Stratton, R.D., Browne, R.W., Rosner, B.A., Lanham, R.J. and Armstrong, D. (2000) Serum Markers of Oxidative Stress and Severity of Diabetic Retinopathy. Diabetes Care, 23, 234-240. http://dx.doi.org/10.2337/diacare.23.2.234

[43] Mancino, R., Di Pierro, D., Varesi, C., Cerulli, A., Feraco, A., Cedrone, C., Pinazo-Duran, M., Coletta, M. and Nucci, C. (2011) Lipid Peroxidation and Total Antioxidant Capacity in Vitreous, Aqueous Humor, and Blood Samples from Patients with Diabetic Retinopathy. Molecular Vision, 17, 1298-1304.

[44] Aldebasi, Y., Mohieldein, A., Almansour, Y. and Almoteri, B. (2011) Imbalance of Oxidant/Antioxidant Status and Risk Factors for Saudi Type 2 Diabetic Patients with Retinopathy. British Journal of Medicine \& Medical Research, 1, 371-384.

[45] Kowluru, R.A. and Koppolu, P. (2002) Termination of Experimental Galactosemia in Rats, and Progression of Retinal Metabolic Abnormalities. Investigative Ophthalmology \& Visual Science, 43, 3287-3291.

[46] Lepira, F.B., M’buyamba Kabangu, J.R., Kayembe, K.P. and Nseka, M.N. (2005) Correlates of Serum Lipids and Lipoprotein in Congolese Patients with Arterial Hypertension. Cardiovascular Journal of South Africa, 16, 249-255.

[47] Seedat, Y.K., Mayet, F.G.H., Latiff, G.H. and Joubert, G. (1993) Study of Risk Factors Leading to Coronary Heart Disease in Urban Zulus. Journal of Human Hypertension, 7, 529-532.

[48] Longo-Mbenza, B., Agongola Mambune, H.F., Kasiam, J.B., Kintoki Vita, E., Mbungu Fuele, S., Nkondi Senga, J., Mabwa, L. and Nzuzi, V. (2008) Positive Correlation between Waist Circumference, HDL-Cholesterol and Total Cho- 
lesterol in Central Africans with Congestive Heart Failure: Reverse Epidemiology and U-Shaped Relationship in Cardiovascular Risk. Circulation, 117, 677.

[49] Bruce, C., Sarp, D.S. and Tall, A.R. (1998) A Relationship of HDL and Coronary Heart Disease to a Common AminoAcid Polymorphism in the Cholesteryl Ester Transfer Protein in Men with and without Hypertriglyceridemia. Journal of Lipid Research, 39, 1071-1078.

[50] Klos, K.L. and Kullo, I.J. (2007) Genetic Determinants of HDL: Monogenic Disorders and Contributions to Variation. Current Opinion in Cardiology, 22, 344-351. http://dx.doi.org/10.1097/HCO.0b013e3281a8acad

[51] Guyard-Dangremont, V., Lagrost, L., Gambert, P. and Lallemant, C. (1994) Competitive Enzyme-Linked Immunosorbent Assay of the Human Cholesteryl Ester Transfer Protein (CETP). Clinica Chimica Acta, 231, 147-160. http://dx.doi.org/10.1016/0009-8981(94)90199-6

[52] Brunham, L.R., Singaraja, R.R. and Hayden, M.R. (2006) Variations on a Gene: Rare and Common Variants in ABCA1 and Their Impact on HDL Cholesterol Levels and Atherosclerosis. Annual Review of Nutrition, 26, 105-129. http://dx.doi.org/10.1146/annurev.nutr.26.061505.111214

[53] Moss, S.E., Klein, R. and Kelin, B.E. (1996) Cigarette Smoking and Ten-Year Progression of Diabetic Retinopathy. Ophthalmology, 103, 1438-1442. http://dx.doi.org/10.1016/S0161-6420(96)30486-7

[54] Sich, D., Saidi, Y., Giral, P., Lagrost, L., Elgloff, M., Auer, C., Gautier, V., Turpin, G. and Beucler, I. (1998) Hyperalphalipoproteinemia: Characterization of a Cardioprotective Profile Associating Increased High-Density Lipoprotein 2 Levels and Decreased Hepatic Lipase Activity. Metabolism, 47, 965-973. http://dx.doi.org/10.1016/S0026-0495(98)90352-3

[55] Tyroler, H.A., Glueck, C.J., Christensen, B. and Kwiterovich Jr., P.O. (1980) Plasma High-Density Lipoprotein Cholesterol Comparisons in Black and White Populations. The Lipid Research Clinics Program Prevalence Study. Circulation, 62, IV99-IV107.

[56] Bower, J.F., Deshaies, Y., Pfeifer, M., Tanenberg, R.J. and Brarkat, H.A. (2002) Ethnic Differences in Postprandial Triglyceride Response to a Fatty Meal and Lipoprotein Lipase in Lean and Obese African American and Caucasian Women. Metabolism, 51, 211-217. http://dx.doi.org/10.1053/meta.2002.29991

[57] Jaichander, P., Selvarajan, K., Garelnabi, M. and Parthasarathy, S. (2008) Induction of Paraoxonase 1 and Apolipoprotein A-1 Gene Expression by Aspririn. Journal of Lipid Research, 49, 2142-2148. http://dx.doi.org/10.1194/jlr.M800082-JLR200

[58] Aviram, M., Rosenblat, M., Bisgaier, C.L., Newton, R.S., Primo-Parmo, S.L. and La Du, B.N. (1998) Paraoxonase Inhibits High-Density Lipoprotein Oxidation and Preserves Its Functions. A Possible Peroxidative Role for Paraoxonase. Journal of Clinical Investigation, 101, 1581-1590. http://dx.doi.org/10.1172/JCI1649 